\title{
Exercise and smoking habits among Swedish postmenopausal women
}

Department of Obstetrics and Gynaecology, Faculty of Health Sciences, University Hospital, S-581 85 Linköping, Sweden

J Frisk

J Brynhildsen

T Ivarsson

P Persson

M Hammar

Correspondence to: Mats Hammar.

Accepted for publication 23 April 1997

\begin{abstract}
Objective-To assess exercise habits and their relation to smoking habits and social and medical factors in postmenopausal women.

Methods-A cross-sectional study with a questionnaire to all 1324 55-56 year old women in Linköping, Sweden.

Results-Response rate was $85 \%$. About a third of the women took part in some kind of quite strenuous exercise for at least one hour a week. About a quarter worked out once a week; fewer did swimming and jogging. One in four women smoked. Women who used hormone replacement therapy, who were not smoking and who had a physically light occupation more often took part in strenuous sports. Women who had been treated for malignancies or with back problems exercised to the same extent as women in the general population.

Conclusion-About a third of the postmenopausal women exercised on a regular basis, if exercise involved in getting to and from work was not counted. Since regular physical exercise has many health benefits, more women should be encouraged to take part in regular physical exercise. Factors probably associated with level of education and general awareness of the importance of a healthy lifestyle positively influenced the likelihood of these women to be physically active on a regular basis. A previous malignant disease or current back problems did not prevent women from taking part in exercise on a regular basis.
\end{abstract}

(Br F Sports Med 1997;31:217-223)

Keywords: menopause; exercise habits; hot flushes; smoking

Menopause is the last menstrual bleed, when ovarian oestradiol production no longer stimulates the endometrium to proliferate. Menopausal age is about 51 years in Western countries. ${ }^{1-4}$ Around menopause most women experience vasomotor symptoms such as hot flushes and sweating, and some years later many women report urogenital symptoms such as dyspareunia, dysuria, and urgency incontinence. ${ }^{1-4}$ The incidence of cardiovascular disease increases from this age, ${ }^{5}$ partly because of loss of the effect of oestrogen on lipoprotein metabolism and vessel wall relaxation. ${ }^{6}$ Bone loss is accelerated, with increased risk of fractures. ${ }^{7}$
Many peri- and post-menopausal women also report depression and other psychological problems, which may be attributed to exogenous factors, but also to hormonal changes. ${ }^{8}$

Most of these symptoms and changes around menopause may be ameliorated or completely cured by oestrogen replacement therapy (ERT), which should be combined with progestagen therapy to avoid hyperstimulation of the endometrium and risk of endometrial carcinoma. ${ }^{9}$ Combined treatment, usually called hormone replacement therapy (HRT), leads to vaginal bleeding, which makes some women abandon the treatment. Other women are prevented from undergoing ERT for medical reasons. Therefore there is a need for alternative treatments. There are relatively few pharmacological alternatives to ERT/HRT. Lifestyle factors such as regular physical activity affect many metabolic changes and symptoms of the climacteric, ${ }^{10}$ including mental status as well as vasomotor symptoms. ${ }^{11}$ In fact, most metabolic changes correlated to the decrease in sex steroids around menopause are affected by exercise in the same direction as by oestrogens, but exercise also has some unique effects. Studies have shown that physically active women have a higher maximal oxygen uptake $^{12-16}$ and a decreased risk of cardiovascular disease and death. ${ }^{17-20}$ Exercise has beneficial effects on weight, ${ }^{21-24}$ lipoprotein metabolism, ${ }^{25} 26$ blood pressure, ${ }^{27-29}$ and glucose tolerance. ${ }^{30-33}$ Furthermore, exercise increases bone mass and prevents bone loss ${ }^{34-36}$ and also benefits balance, ${ }^{37}$ which should decrease the risk of falls and fractures. Fewer physically active women were found to have moderate to severe hot flushes after menopause than age matched women from a control group. ${ }^{38}$ Physical activity also exerts mental effects reducing both anxiety and physiological arousal,,$^{39}$ has definite relaxing effects, ${ }^{40}$ and appears to be an efficient treatment for mild to moderate depression. ${ }^{4142}$

During the past few decades the number of competitive sports available to women has increased as has women's general leisure time for physical activity. ${ }^{43}$ Women may even have increased their activity levels more than men, and this also includes older women. ${ }^{43}$ The mean age of joggers has been found to increase, perhaps the result of a cohort phenomenon. ${ }^{44}$ Although interest in physical activity is growing, only $7-8 \%$ of women and men in the US aged 18-65 years were found to take part in regular physical exercise that involved large muscle groups for at least $60 \%$ of the 
cardiorespiratory capacity for more than 20 minutes, three times a week. ${ }^{45}$

Although we now know that regular exercise has a number of beneficial effects on the periand post-menopausal woman, we do not know to what extent women of these ages actually take part in different kinds of exercise and which women are active. Smokers have an earlier menopause and also seem to metabolise endogenous as well as orally administered oestrogens more rapidly. Therefore, apart from the negative effects of smoking in itself, smokers may have more pronounced symptoms and metabolic changes after menopause than nonsmokers. Smoking is influenced by social factors, and women are less likely to smoke if married than if divorced, widowed, or single. ${ }^{46-49}$ Smoking seems to be common even among postmenopausal women, and $25-38 \%$ of Swedish women of postmenopausal age were smokers in the early $1980 \mathrm{~s}^{5051}$ Therefore, it is important to include smoking habits in a survey on lifestyle factors in postmenopausal women.

The objective of this study was to assess exercise and smoking habits in peri- and postmenopausal Swedish women in relation to other health factors.

\section{Methods}

In early 1995 a questionnaire was sent to all 1324 women residing in Linköping, who would be 55 or 56 years old during that year. Their names and addresses were obtained from the Swedish population register. A postal reminder was sent after two months. Some of the unclear answers and unanswered questions were sent back to be returned after correction or completion.

The questionnaire covered occupation, parity, time of last menstruation, gynaecological operations, climacteric complaints, use of HRT, body length, and weight. All women were asked about smoking and exercise habits. They were asked if they exercised on a regular basis, including cycling or walking to and from work. They were also asked to give the number of hours per week spent on a number of different kinds of sport. We had chosen working out, jogging, swimming, walking, and cycling. They were also asked to give the number of hours spent on other kinds of exercise and what they were.

In this way we received separate data for a number of different sporting activities from each woman. In order to obtain the total number of hours per week dedicated to the more strenuous sports, we added up the number of hours each woman spent on jogging, swimming, and working out. The women were also asked to specify other sports and types of exercise undertaken. Many listed activities such as gardening and golf under "other" exercise, but these were not included in the total sum as they were not considered to be energetic enough to affect pulse rate or oxygen consumption significantly. If the subject regularly spent time cycling, that time was divided by two before it was included in "total" time, because we considered that cycling is usually less energetic than the other sports, especially as most women used cycling as a means of transport to and from work. Walking was not included in the "total" sum.

The questionnaire was validated by letting five randomly selected healthy women of periand post-menopausal age answer it in writing. These women were then interviewed in order to find possible misinterpretations, so that the questions could be made easier and clearer.

\section{DATA HANDLING AND STATISTICS}

The questionnaires were coded and remained so when data were analysed using Macintosh Statview 4.1 (Abacus Concepts Inc). $\chi^{2}$ Test or Wilcoxon rank sum test was used for analysis of differences between groups, and contingency analyses were performed when categorised data with more than two categories were compared.

\section{ETHICS}

The study was approved by the local ethical committee of the University of Linköping.

\section{Results}

Of the 1324 questionnaires sent, $1122(84.7 \%)$ were answered after one postal reminder, albeit all not completely. All questions about exercise were answered by 1107 women.

The women had on average 2.03 children (range 0-10). Body mass index (BMI) was 24.7 (4.0) (mean (SD)); median and 25th and 75th percentiles were 24.15 and 21.9-26.5. Median time since menopause was four years (25th to 75 th percentiles were $1.9-6.5$ years); about $90 \%$ were postmenopausal-that is, at least one year since the last menstrual bleed. Almost $9 \%$ of the women had experienced a surgical menopause - that is, undergone hysterectomy with or without bilateral oophorectomy. About $35 \%$ of the women currently used HRT, half of them for at least two years; only $5 \%$ had tried HRT and abandoned it. About $5 \%$ used herbal and alternative remedies to relieve climacteric symptoms, and another $15 \%$ had tried such therapies and abandoned them mainly because of insufficient effects.

Two thirds of the women never used any medication (other than HRT), but $8 \%$ used analgesics, $6 \%$ antihypertensive medication, and $4 \%$ had treatment for bronchial asthma. About $2 \%$ used sedatives now and then, and another $0.5 \%$ used sedatives because .of disturbed sleep caused by climacteric symptoms. Some $4 \%$ used thyroxine, and $1 \%$ had diabetes.

Table 1 summarises the exercise habits. It appeared that the most popular specific sports were working out and swimming, but a large number of women spent at least one hour a week walking $(84.3 \%)$ or cycling $(46.9 \%)$, often as a method of transport between home and work. In all therefore most women undertook some physical activity every week, and 57 women $(5 \%)$ spent at least four hours every week on exercise. When we calculated the "total" number of hours per week spent on exercise, we omitted walking and divided hours cycling by 2 , which explains the apparent 
discrepancy between the figures for separate sports and the "total" sum in table 1. Only about every third woman did not exercise at all (see the "total" column in table 1), and two thirds exercised at least one hour per week. About $16 \%$ of women took part in other kinds of exercise, such as riding, tennis, golf, and bowling.

When looking at more specific sports, we only included jogging, swimming, and working out. Forty women $(3.6 \%)$ jogged at least one hour a week, 103 women $(9.3 \%)$ spent at least one hour per week on swimming and 245 women $(22.1 \%)$ at least one hour per week working out (table 1). Some women exercised regularly participating in more than one of these different sports, but $343(31.0 \%)$ practised one of the more intense sports on a regular basis at least once a week and $101(9.1 \%)$ for two hours or more a week (table 1 ).

\section{SMOKING HABITS AND EFFECT OF SMOKING ON EXERCISE}

About a quarter of the women were smokers, a quarter had previously smoked but stopped, and the rest had never smoked (table 2).

BMI was slightly lower for smokers than non-smokers (mean $23.9 v 24.9 ; \mathrm{P}=0.013$; Student's $t$ test). There was a weak, but significant, negative correlation between time/week spent on exercise and BMI $(r=-0.15$; $\mathrm{P}<0.01$ ).

Regular exercise, counting all kinds of exercise for at least one hour/week ("Total"; table 1), was significantly more common

Table 1 Exercise habits among 55 and 56 year old women from Linköping, Sweden. The column "total" includes the sum for each woman of the hours spent jogging (F), swimming (S), and working out (W), and more intense "other"sports and also hours spent cycling divided by 2. Time spent on less intense "other" sports and walking are not included in the "total"

\begin{tabular}{llllllllll}
\hline $\begin{array}{l}\text { Time spent } \\
\text { (hours/ } \\
\text { week) }\end{array}$ & \multicolumn{1}{l}{\begin{tabular}{l} 
Percentage \\
\cline { 2 - 9 }
\end{tabular}} & Walking & fogging & Swimming & Working out & Cycling & Other & f+S+W & Total \\
\hline No exercise & 15.7 & 96.4 & 90.7 & 77.9 & 53.1 & 84.0 & 69.0 & 34.3 \\
$1-<2 \mathrm{~h} / \mathrm{w}$ & 28.0 & 2.5 & 8.4 & 17.6 & 16.7 & 8.2 & 21.9 & 34.3 \\
$2-<3 \mathrm{~h} / \mathrm{w}$ & 23.6 & 0.6 & 0.5 & 3.5 & 10.7 & 3.5 & 6.5 & 19.7 \\
$\geqslant 3 \mathrm{~h} / \mathrm{w}$ & 32.7 & 0.5 & 0.4 & 1.0 & 19.5 & 4.3 & 2.6 & 11.7 \\
\hline
\end{tabular}

Table 2 Percentage of 55 and 56 year old women taking part in different kinds of exercise at least one hour/week in relation to smoking. The number of women who both answered about smoking and number of hours participation in a certain sport varied a little between different sports, which is shown as a range under " $N$ ". The column "total" includes the sum for each woman of the hours spent on jogging, swimming, and working out, and more intense "other" sports and also hours spent cycling divided by 2. Time spent on less intense "other" sports and walking are not included in the "total"

\begin{tabular}{lrlllllll}
\hline \multicolumn{7}{c}{ Percentage } \\
\cline { 2 - 9 } Smoking habits & $N$ & $\begin{array}{l}\text { Working } \\
\text { out }\end{array}$ & fogging & Walking & Cycling & Swimming & Other & Total \\
\hline $\begin{array}{l}\text { Never } \\
\text { Finished > 5 } \\
\text { years ago }\end{array}$ & $552-556$ & 25.2 & 4.5 & 85.8 & 49.6 & 10.3 & 15.7 & 67.9 \\
$\begin{array}{c}\text { Finished 1-5 } \\
\text { years ago }\end{array}$ & $202-203$ & 25.6 & 3.0 & 82.8 & 48.0 & 9.9 & 18.2 & 69.5 \\
$\begin{array}{c}\text { Finished < 1 } \\
\text { years ago }\end{array}$ & 57 & 22.8 & 0 & 80.7 & 49.1 & 12.3 & 17.5 & 77.2 \\
$\begin{array}{c}\text { Smokes 1-5 per } \\
\text { day }\end{array}$ & 19 & 21.1 & 5.3 & 89.5 & 47.4 & 5.3 & 26.3 & 73.7 \\
$\begin{array}{c}\text { Smokes 6-19 } \\
\text { per day }\end{array}$ & $177-74$ & 16.2 & 5.4 & 83.8 & 44.6 & 5.5 & 16.2 & 64.9 \\
$\begin{array}{c}\text { Smokes > 19 } \\
\text { per day }\end{array}$ & 12 & 8.3 & 0 & 91.7 & 16.7 & 16.7 & 16.7 & 41.7 \\
\hline
\end{tabular}

among non-smokers (69.1\%) than among smokers $\left(55.6 \% ; \chi^{2}=14.8\right.$ with Yates's correction; $\mathrm{P}<0.001$ ). Non-smokers tended to be more active in all different sports, and the difference reached statistical significance for working out, whereas twice as many nonsmokers than smokers $(25 \% v 12.5 \%)$ were active for at least one hour/week $\left(\chi^{2}=17.3\right.$; $\mathrm{P}<0.001)$. The longer the time since the women had quit smoking, the higher the prevalence of active women working out (table $2)$. The more cigarettes per day women smoked, the less likely they were to work out (contingency analysis $\chi^{2}=38.45 ; P=0.0034$ ). For other sporting activities this tendency was less evident. Most women (81-92\%) spent at least one hour/week walking, no matter whether they were smokers or not (table 2).

\section{SOCIAL AND OTHER FACTORS AND THEIR}

ASSOCIATION WITH EXERCISE

There was no correlation between parity and number of hours/week spent on exercise $(r=-$ 0.013 , simple regression analysis).

Women were asked to classify their occupation as physically light (44\%), moderately heavy (35\%), or heavy ( $9 \%)$. About $10 \%$ had retired prematurely because of a somatic or psychiatric chronic disease and $2.4 \%$ were housewives (table 3). The women were not asked about satisfaction with work or total working time per week.

Participation in jogging and working out was associated with the type of work. About $5 \%$ of women with light or moderately heavy occupations spent one hour/week or more jogging, whereas neither women with a heavy occupation nor retired women jogged. A quarter of women with a light occupation worked out, but only half as many $(13 \%)$ of those with a heavy occupation $\left(\chi^{2}=5.98\right.$ with Yates's correction, $\mathrm{P}<0.05)$. No housewives worked out whereas prematurely retired women worked out to the same extent as other women (table 3 ).

Besides jogging and working out, there were no general differences with regard to how many women took part in physical exercise between those with light and heavy occupations (table 3). Even women who were prematurely retired because of illness were as active as the othersthat is, two thirds took part in some kind of regular exercise including walking and cycling. The housewives differed, only one third being physically active for at least one hour per week, compared with two thirds of women who worked outside their homes $\left(\chi^{2}=14.1\right.$; $P<0.001)$.

\section{MEDICAL FACTORS AND THEIR RELATION TO} EXERCISE

About a third of the women used HRT and these took part in some kind of regular exercise significantly more often ( $72 \%$ ) than non-users $\left(64 \% ; \chi^{2}=8.34 ; P<0.01\right)$. Working out seemed to be particularly attractive to women using HRT; $29.6 \%$ of the 382 HRT users took part in workout sessions at least once a week, compared with $18.0 \%$ of women who did not use medication for climacteric symptoms $\left(\chi^{2}=\right.$ 
Table 3 Percentage of women taking part in different kinds of exercise at least one hour/week in relation to occupation. The number of women who both answered about occupation and number of hours participation in a certain sport varied a little between different sports, which is shown as a range under " $N$ ". The column "total" includes the sum for each woman of the hours spent jogging, swimming, and working out, and more intense "other" sports and also hours spent cycling divided by 2. Time spent on less intense "other" sports and walking are not included in the "total"

\begin{tabular}{lllllllll}
\hline \multicolumn{7}{c}{ Occupation } & \multicolumn{7}{c}{ Percentage } \\
\cline { 3 - 9 } & $N$ & Working out & fogging & Walking & Cycling & Swimming & Other & Total \\
\hline Light & $480-483$ & 25.6 & 5.4 & 86.5 & 43.4 & 8.5 & 18.8 & 66.5 \\
Moderately heavy & $378-380$ & 22.1 & 3.2 & 79.2 & 55.3 & 10.8 & 15.1 & 71.6 \\
Heavy & $100-101$ & 13.0 & 0 & 91.1 & 49.5 & 6.9 & 13.0 & 61.4 \\
Prematurely retired & $105-106$ & 22.6 & 0.9 & 84.9 & 37.7 & 9.5 & 11.3 & 56.2 \\
Housewife & $26-27$ & 0 & 0 & 92.3 & 33.3 & 7.4 & 11.1 & 33.3 \\
\hline
\end{tabular}

18.3; $\mathrm{P}<0.001)$. For the other different sports there were no significant differences.

Women who had previously used oral contraceptives (64\%) took part in regular exercise slightly, but significantly, more often than women who had not used oral contraceptives $\left(68.4 \%\right.$ v $\left.60.4 \% ; \chi^{2}=7.21 ; P<0.01\right)$.

Physical activity among women who used no medication such as analgesics, antihypertensives, thyroxine, and antidiabetic drugs was compared with that of women who did use such medications. Contingency analyses showed women not taking medication to be significantly more active with respect to jogging $(P=0.029)$, cycling $(P=0.0002)$ and overall $(P=0.008)$, whereas they did not differ with respect to walking, working out, and swimming.

Sixty eight women had been treated for a uterine or breast malignancy, but this fact did not prevent them from taking part in regular exercise. Thus women treated for malignancies took part in exercise to the same extent as women in general.

Neither did previous premenstrual symptoms during the fertile period affect to what extent women were physically active.

Almost half of the women had suffered from back problems during the recent period, but these problems did not influence their exercise habits. Even women with moderate to severe back problems exercised to the same extent as women without these symptoms.

There was no relation between exercise habits and the occurrence of hot flushes (table 4). In fact, quite a few $(12 \%)$ women had moderate to severe hot flushes at the time of the survey, probably because every third woman used HRT.

\section{Discussion}

The use of an unselected population is important for most epidemiological studies, especially as the purpose in this study was to obtain a general impression of the population at this

Table 4 Participation in different sports on a regular basis for at least one hour/week among women with and without vasomotor symptoms. There were no significant differences between those with and without vasomotor symptoms

\begin{tabular}{llll}
\hline & \multicolumn{2}{l}{ Percentage } \\
\cline { 2 - 4 } & fogging & Swimming & Working out \\
\hline $\begin{array}{l}\text { Vasomotor symptoms } \\
\begin{array}{l}\text { No vasomotor } \\
\text { symptoms }\end{array}\end{array}$ & 3.0 & 10.0 & 21.6 \\
\hline
\end{tabular}

age. We consider our group large enough to be representative and that the low drop out rate $(15 \%)$ did not affect the results markedly. Therefore we did not perform any drop out analysis. We assume that no women were missed since the Swedish population register is extremely accurate. Since the various questions had been tested beforehand and were easy to understand, we also consider the answers to be valid. There is a risk that the women overestimated the time spent on the different sports, and underestimated for example the number of cigarettes smoked per day, but that is a general problem in questionnaire studies. A personal interview would probably not overcome this problem, and there were no differences between the written and oral answers among the women who were interviewed after having filled in the questionnaire. A prospective study on exercise habits would avoid recall bias, but would probably in itself affect the exercise habits during the course of the study.

The time spent on separate sporting activities is probably fairly correct whereas our "total sum" (table 1) is arbitrary, since we have tried to estimate for each woman the number of hours spent on the more intensive sports and have omitted "walking", divided the number of hours spent cycling by 2 , and omitted some of the "other" less energetic physical activities. These data should therefore be considered with caution. Other reasons to be careful with the interpretations is the fact that all data are self reported, intensity of physical activity is not defined, and systems to classify degree and type of exercise are lacking. An ideal study would include measurement of the intensity of exercise for each woman and sport, but this is of course impossible in a large cross sectional questionnaire study.

We found that about a third of the women dedicated at least one hour a week to fairly strenuous exercise-that is, jogging, swimming, and working out - and this rose to two thirds when we included other sports such as tennis and cycling. This is a rather high figure compared with the few data we have from other studies. White and coworkers ${ }^{52}$ found that $14 \%$ of 1472 English women aged 55-70 years exercised at an optimal level (at least three 20 minute sessions per week of moderate to vigorous activity), $23 \%$ at a suboptimal level, and $63 \%$ were sedentary-that is, no sporting activity. ${ }^{52}$ They found that $72 \%$ took part in physical activity for more than 30 minutes daily, when walking was included. 
Kolanowski and coworkers ${ }^{53}$ found that $7 \%$ of 51-85 year old members of a "ladies' club" went swimming and jogging at least twice a week. Probably these women, being active members of a club, were more active than women from the general population, but the result is similar to ours for the general population, where we found $9 \%$ to be active in more strenuous sports for at least two hours per week. It should be emphasised, however, that our study looked at a narrower and younger population than that of Kolanowski and coworkers. ${ }^{53}$ We found that exercise habits correlated with a number of factors. Women who smoked took part in workout sessions less often, which is in accordance with previous studies. ${ }^{5254-56}$

Physically active women had a slightly lower BMI than sedentary women, which confirms previous reports on exercise and body weight. ${ }^{57}$ The correlation was, however, weak, probably because women who smoked, who were generally less physically active, also had a lower BMI than non-smokers. This is in accordance with previous studies on women of similar age, which also reported lower BMI among smokers, ${ }^{50-60}$, whereas heavy smokers have been reported to be generally heavier..$^{5061}$

Women who were currently using HRT were more physically active, in particular working out. Today many women are aware of the health benefits from the use of HRT and the association between use of HRT and exercise habits suggests a general awareness of health benefits among these women.

Unfortunately we did not ask the women about their education, but only asked them to classify their kind of work as light or heavy. An occupation that is classified as light also often requires a longer education than a heavy occupation. If that is true, the association between light occupation and a high exercise level supports the hypothesis that educated women with greater awareness of healthy lifestyle factors are more likely to take part in physical exercise. Naturally, a woman doing heavy work may feel that she has had her "dose" of exercise at work and wants to use her leisure time for something else.

Premenstrual symptoms may be diminished by exercise ${ }^{6263}$ and thus women with such symptoms, who may spontaneously have noticed this phenomenon, may take up exercise. Women who reported previous premenstrual symptoms, however, did not take part in exercise more often than other women.

Fortunately women who suffered from back problems and women treated for malignancies were not prevented from taking part in physical exercise, but were as active as women in general. In fact, there are some epidemiological data suggesting that exercise can help to prevent some cancers, such as those of the colon, ${ }^{64}$ endometrium, ${ }^{65}$ and breast. ${ }^{66}{ }^{67}$ Most postmenopausal women experience vasomotor symptoms with hot flushes and sweating. ${ }^{1-3}$ Many phenomena measured during the hot flush could be explained by an instability and a sudden resetting of the thermoregulatory centre, in order to decrease central body temperature. If impairment of central opioid activity makes the thermoregulation labile ${ }^{68-70}$ and thereby provokes hot flushes, then mechanisms that increase central opioid activity, such as regular physical activity, ${ }^{71}$ might diminish the frequency of hot flushes. In a previous study we found that the prevalence of vasomotor symptoms was lower among physically active postmenopausal women than among women in general. ${ }^{38}$ In the present study we could not confirm a lower prevalence of vasomotor symptoms among the physically active women. This may, at least in part, be explained by the fact that a third of all women had HRT, usually because of vasomotor symptoms. Thus quite a few women had hot flushes during the study, and women who avoided HRT despite hot flushes are probably a selected group.

The most common cause of morbidity and mortality among postmenopausal women is cardiovascular disease. Exercise seems to decrease the risk of cardiovascular disease through several different mechanisms, ${ }^{20} 7273$ but in clinical practice the net effect in the individual patient is what is important. Most men and women, including most peri- and post-menopausal women, undertake little physical activity in their everyday life and work. Thus it is of great importance for women to take part in exercise and sport in their spare time, which would probably have beneficial effects with regard to cardiovascular disease. Thus many of the metabolic changes and risk factors for cardiovascular disease and fractures that appear around the menopause may be more or less counteracted by physical exercise, as are problems with anxiety and depression. Even vasomotor symptoms are less prevalent in exercising women. These effects of exercise are often of the same magnitude as those induced by ERT, ${ }^{11}$ but exercise may also have additional beneficial effects.

The positive effects of exercise are affected by other factors such as general awareness of lifestyle, diet, and smoking habits. Many, but not all, studies compensate for such confounders, but there is still a great need for prospective randomised studies before definite conclusions can be drawn as to the benefits of exercise (and oestrogens) on well being and various health factors. Furthermore, it is not known whether beneficial effects of exercise are additive to those induced by ERT. To motivate women to exercise it is necessary to select exercise that is of interest and enjoyable. Also the exercise has to be adapted to the woman's physical and socioeconomic circumstances. Compliance is the key to success.

Recommendations for regular physical exercise and an active lifestyle, especially in our sedentary modern westernised society are needed. Peri- and post-menopausal women not on ERT or HRT would probably benefit more from regular exercise than other women in general. The rather high prevalence of exercise in the present study is positive, but still much has to be done to encourage more women to take part in regular exercise with important preventive health effects. 
We are indebted to medical students Constance Skarsgård and Erika Björs for assistance with data collection and to Förenade Liv Mutual Group Life Insurance Company Stockholm and Lion's Foundation for financial support.

1 McKinlay SM, Brambilla DJ, Posner JG. The normal menopause transition. Maturitas 1992;14:103-15.

2 Berg G, Gottvall T, Hammar M, Lindgren R. Climacteric symptoms among women aged 60-62 in Linköping, Sweden, in 1986. Maturitas 1988;10:193-9.

3 Hammar M, Berg G, Fåhraeus L, Larsson-Cohn U. Climacteric symptoms in an unselected sample of Swedish women. Maturitas 1984;6:345-50.

4 Lindgren R, Berg G, Hammar M, Zuccon E. Hormonal replacement therapy and sexuality in a population of Swedish postmenopausal women. Acta Obstet Gynecol Scand 1993;72:292-7.

5 Wilhelmsen L, Johansson S, Ulvenstam G, Welin L, Rosengren A, Eriksson H, et al. CHD in Sweden: mortality, inicidence and risk factors over 20 years in Gothenburg. Int Epidemiol 1989;18:101-8.

6 Weiner CP, Lizasoain I, Baylis SA, Knowles RG, Charles IG, Moncada S. Induction of calcium-dependent nitric oxide synthase by sex hormones. Proc Natl Acad Sci USA 1994;91:5212-6.

7 Cummings SR, Kelsey JL, Nevitt MC, O'Dowd KJ. Epidemiology of osteoporosis and osteoporotic fractures. Epidemiol Rev 1985; 7:178-208.

8 Dennerstein L. Psychiatric aspects of the climacteric. In: Studd JWW, Whitehead MI, eds. The menopause. Oxford: Blackwell Scientific Publications, 1988:43-54.

9 Leather AT, Studd JWW. Can the withdrawal bleed following oestrogen replacement therapy be avoided? $\mathrm{Br} \mathcal{F}$ Obstet Gynecol 1990;97:1071-9.

10 Notelovitz $M$. The non-hormonal management of the menopause. In: Studd J, Whitehead M, eds. The menopause. Oxford: Blackwell Scientific Publications, 1988:102-15.

11 Hammar M, Brynhildsen J, Wyon Y, Nedstrand E, Notelovitz $M$. The effects of physical activity on menopausal symptoms and metabolic changes around menopause. Menopause 1995;2:201-9.

12 Drinkwater BL, Horvath SM, Wells CL. Aerobic power of females ages 10 to 68 . F Gerontol 1975;30:385-94.

13 Drinkwater BL. Assessing fitness and activity patterns of women in general population studies. In: Dury,ed. Assessing physical fitness and physical activity in population-based surveys. Washington DC: Public Health Service, 1989:26171.

14 Notelovitz $M$, Fields C, Caramelli K, Dougherty $M$, Schwartz AL. Cardiorespiratory fitness evaluation in
climacteric women: comparison of two methods. $A m \mathcal{f}$ Climacteric women: comparison

15 Hagberg JM, Graves JE, Limacher M, Woods DR, Leggett $\mathrm{SH}$, Cononie C, et al. Cardiovascular responses of 70-79 year old men and women to exercise training. $\mathcal{f} A$ ppl Physiol 1989;66:2589-94.

16 Probart CK, Notelovitz M, Martin D, Khan FY, Fields C. The effect of moderate aerobic exercise on physical fitness among women 70 years and older. Maturitas 1991;14:4956.

17 Scragg R, Stewart A, Jackson R, Beaglehole R. Alcohol and exercise in myocardial infarction and sudden coronary death in men and women. Am 7 Epidemiol 1987;126:77-85.

18 Magnus $\mathrm{K}$, Matroos A, StrackeeJ. Walking, cycling or gardening, with or without seasonal interruption, in relation to acute coronary events. Am $\mathcal{f}$ Epidemiol 1979;110:724-33.

19 Blair SN, Kohl HW, Pfaffenberger RS, Clark DG, Cooper $\mathrm{KH}$, Gibbons LW. Physical fitness and all-cause mortality: a prospective study of healthy men and women. $\Im A M A$ 1989;262:2395-401.

20 Owens JF, Matthews KA, Wing RR, Kuller LH. Physical activity and cardiovascular risk: a cross-sectional study of middle-aged premenopausal women. Prev Med 1990;19: 147-57.

21 Upton SJ, Hagan RD, Lease B, Rosentswieg J, Gettman LR, Duncan JJ. Comparative physiological profiles among young and middle-aged female distance runners. Med Sci Sports Exerc 1984;16:67-71.

22 Marti B, Salonen JT, Tuomiletho J, Puska P. 10-year trends in physical activity in the eastern Finnish adult population: relationship to socioeconomic and lifestyle characteristics. Acta Med Scand 1988;224:195-203.

23 Marti B. Benefits and risks of running among women: an epidemiologic study. Int $\mathcal{F}$ Sports Med 1988;9:92-8.

24 Gwinup G. Weight loss without dietary restriction: efficacy of different forms of aerobic exercise. Am $\mathcal{F}$ Sports Med 1987;15:275-9.

25 Lindheim S, Notelovitz M, Feldman E, Larsen S, Khan F, Lobo $R$. The independent effects of exercise and estrogen on lipids and lipoproteins in postmenopausal women. Obstet Gynecol 1994;83:167-72.

26 Hardman AE, Hudson A, Jones PR, Norgan NG. Brisk walking and plasma high density lipoprotein concentration in previously sedentary women. $B M \mathcal{F} 1989 ; 299: 1204-5$.

27 Cononie CL, Graves JE, Pollock ML, Phillips MI, Sumners C, Hagberg JM. Effect of exercise training on blood pressure in 70-79-year-old men and women. Med Sci Sport Exerc 1991;23:505-11.
28 Saar E, Chayot R, Meyerstein N. Physical activity and blood pressure in normotensive young women. Eur $\mathcal{F}$ Appl Physiol 1986;55:64-7.

29 Blair SN, Goodyear NN, Gibbons LW, Cooper KH. Physical fitness and incidence of hypertension in healthy normocal fitness and incidence of hypertension in healthy

30 Frisch RE, Wyshak G, Albright NL, Albright TE, Schiff I. Lower prevalence of diabetes in female former athletes compared with nonathletes. Diabetes 1986;35:1101-5.

31 King DS, Dalsky GP, Staten MA, Clutter WE, van Houten DR, Holloszy J. Insulin action and secretion in endurance trained and untrained humans. $\mathcal{F}$ Appl Physiol 1987;63: 2247-52.

32 Krotkiewski M, Björntorp P. Muscle tissue in obesity with different distribution of adipose tissue: effect of physical different distribution of adipose tiss

33 Lamarche B, Deprés JP, Pouliot MC, Moorjani S, Lupien PJ, Thériault $\mathrm{G}$ et al. Is the body fat loss a determinant factor in the improvement of carbohydrate and lipid metabolism following aerobic exercise training in obese women? Metabolism 1992;41:1249-56.

34 Martin D, Notelovitz M. Effects of aerobic training on bone mineral density of postmenopausal women. 7 Bone Miner Res 1993;8:931-6.

35 Rikli RE, McManis BG. Effects of exercise on bone mineral content in postmenopausal women. Res $Q$ Exerc Sport 1990;61:243-9.

36 Notelovitz M, Martin D, Tesar R, Khan F Y, Probart C, Fields $\mathrm{C}$ et al. Estrogen therapy and variable-resistance weight training increase bone mineral in surgically menopausal women. F Bone Miner Res 1991;6:583-90.

37 Ledin T, Kronhed A, Möller C, Möller M, Ödkvist L, Olsson B. Effects of balance training in elderly evaluated by clinical tests and dynamic posturography. $\mathcal{F}$ Vestib Res 1991; 1:129-38.

38 Hammar M, Berg G, Lindgren R. Does physical exercise influence the frequency of postmenopausal hot flushes? Acta Obstet Gynecol Scand 1990;69:409-12.

39 Raglin JS, Morgan WP. Influence of exercise and quiet rest on state anxiety and blood preassure. Med Sci Sports Exerc 1987;19:456-83.

40 Petruzello SJ, Landers DM, Hatfield BD, Kubitz KA, Salazar W. A meta-analysis on the anxiety-reducing effects of acute and chronic exercise. Sports Med 1991;11:143-82.

41 Martinsen AW. Benefits of exercise for the treatment of depression. Sports Med 1990;9:380-9.

42 LaFontaine TP, DiLorenzo TM, Frensch PA, Stucky-Ropp RC, Bargman EP, McDonald DG. Aerobic exercise and mood. A brief review, 1985-1990. Leading article. Sports Med 1992;13:160-70.

43 Stephens T. Secular trends in adult physical activity: exercise boom or bust? Res $Q$ Exerc Sport 1987;58:94-105.

44 Marti B, Vader JP. Joggers grow old. Correspondence. Lancet $1987 ; 1207$.

45 Caspersen CJ, Christenson GM, Pollard RA. Status of the 1990 physical fitness and exercise objectives: evidence from NHIS 1985. Public Health Reports 1986;101:587-92.

46 Markides KS, Coreil J, Ray LA. Smoking among MexicanAmericans. A three-generations study. Am $\mathcal{F}$ Publ Health 1987;77:708-11.

47 Novotny TE, Warner KE, Kendrick JS, Remington PL. Smoking by blacks and whites: socioeconomic and demographic differences. Am f Publ Health 1988;78: 1187-9.

48 Orleans CT, Schoenbach UJ, Salmon MA, Stretcher VJ, Kalsbeek W, Quade D, et al. A survey of smoking and quitting patterns among black Americans. Am $\mathcal{f}$ Publ Health 1989;79:176-81.

49 Khosla T, Lowe CR. Obesity and smoking habits by social class. British fournal of Preventive and Social Medicine 1972; 26:249-56.

50 Noppa H, Bengtsson C. Obesity in relation to smoking: a population study of women in Göteborg, Sweden. Prev Med 1980;9:534-43.

51 Berggren G, Sjöstedt S. Rökvanor bland kvinnor belysta med en studie i Öste.

52 White JA, Roberts H, Weller D, Davies P. Adult physical activity patterns and lifestyle factors. In: Atkinson G, Reilly T, eds. Sports, leisure and ergonomics. London: E \& FN Spon, 1995:274-80.

53 Kolanowski AM, Gunter LM. Do retired career women exercise? German Nurse 1988;350-2.

54 Conway TL, Cronan TA. Smoking, exercise and physical fitness. Prev Med 1992;21:723-34

55 Perkins KA, Rohay J, Meilahn EN, Wing RR, Matthews KA, Kuller LH. Diet, alcohol and physical activity as a function of smoking status in middle-aged women. Health Psychol 1993;12:410-15.

56 Klesges RC, Eck LH, Isbell TR, Fulliton W, Hanson CL. The effects of smoking status on the dietary intake, physical activity and

57 Barlow CE, Kohl HW, Gibbons LW, Blair SN. Physical fitness, mortality and obesity. Int f Obes 1995;19:41-4.

58 Ashwell M, North WRS, Meade TW. Social class, smoking and obesity. British fournal of Medicine 1978; 2:1466-7.

99 Albanes D, Jones DY, Mcozzi MS, Mattson ME. Association between smoking and bodyweight in the U.S. population. Analysis of NHANES II. Am $\mathcal{F}$ Public Health 1987;77:43944. 
60 Shimokata H, Muller DC, Andres R. Studies in the distribution of bodyfat III. Effects of cigarette smoking. fAMA 1989;261:1169-73.

61 Istvan J, Cunningham TW, Garfinkel L. Cigarette smoking and bodyweight in the Cancer Prevention Study I. Int $\mathscr{f}$ Epidemiol 1992;21:849-53.

62 Steege JF, Blumenthal JA. The effects of aerobic exercise on premenstrual symptoms in middle-aged women: a prelimipremenstrual symptoms in middle-aged wom
nary study. $\mathcal{F}$ Psychosom Res 1993;37:127-33.

63 Aganoff JA, Boyle GJ. Aerobic exercise, mood states and menstrual cycle symptoms. F Psychosom Res 1994;38:18392.

64 Sternfeld B. Cancer and protective effect of physical activity: the epidemiological evidence. Med Sci Sports Med 1992;24 $1195-209$.

65 Levi F, La Vecchia C, Negri E. Selected physical activities and the risk of endometrial cancer. $\mathrm{Br} \mathcal{F}$ Cancer 1993;67: 846-51.

66 Vihko VJ, Apter DL, Pukkala EI. Risk of breast cancer among female teachers of physical education and lanamong female teachers of physical

67 Bernstein L, Henderson B, Hanisch R, Sullivan-Lalley J Ross R. Physical exercise and reduced risk of breast cancer in young women. $\mathcal{F}$ Natl Cancer Inst 1994;89:1403-8.

68 Tepper R, Neri A, Kaufman H, Shoenfeld A, Ovadia J. Menopausal hot flushes and plasma ß-endorphins. Obstet Gynecol 1987;70:150-2.

69 Shoupe D, Lobo R. Endogenous opioids in the menopause. In: Speroff L, Lobo R, eds. Role of opioid peptides in reproductive endocrinology. Seminars in reproductive endocrinology. Vol 5, No 2. New York: Thieme Medical Publishers, 1987:199-206.

70 Aleem A, McIntosh T. Menopausal syndrome: plasma levels of $B$-endorphin in post-menopausal women measured by a specific radioimmunoassay. Maturitas 1985;7:329-34.

71 Cumming D, Wheeler G. Opioids in exercise physiology. In Speroff $\mathrm{L}$, Lobo $\mathrm{R}$, eds. Role of opioid peptides in reproductive endocrinology. Seminars in reproductive endocrinologyy. Vol 5 , No 2, New York: Thieme Medical Publishers, 1987:17179.

72 Owens JF, Mathews KA, Wing RR, Kuller LH. Can physica activity mitigate the effects of aging in middle aged women Circulation 1992;85:265-70.

73 Meilahn EN, Becker RC, Corrao JM. Primary prevention of coronary heart disease in women. Cardiology 1995;86:286-9.

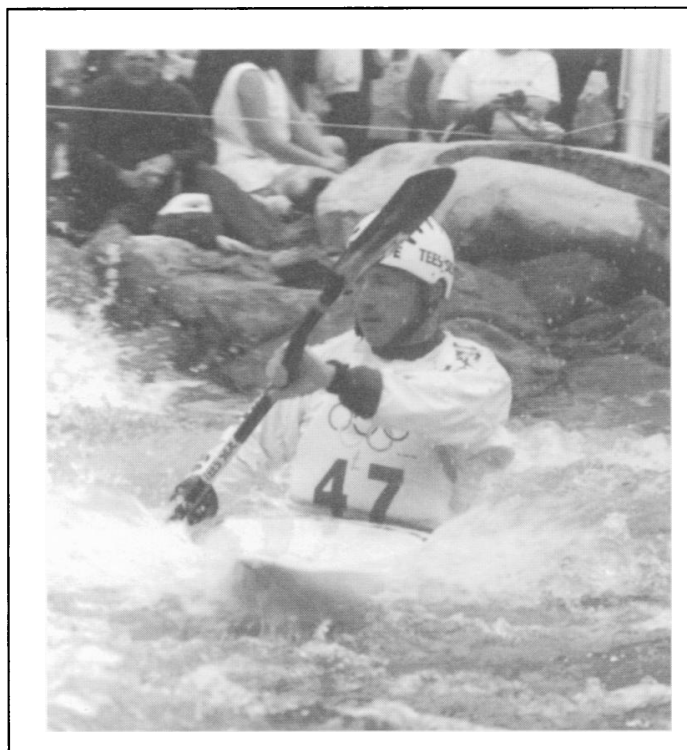

Figure 1 White water slalom course, Nottingham.

\section{Bugs and boats: an athlete's view}

As an athlete involved in a water sport many people ask if I am worried about Weil's disease (leptospirosis) or if it occurs often in canoeing.

Most of our elite athletes train twice a day on the white water slalom course in Nottingham (fig 1), but may also use water pools, canals, or rivers as flat water training sites. Weil's disease is more likely to be caught when canoeing on stagnant water, so there is some risk of exposure. For regular water users there is the possibility of subclinical infection not severe enough to be recognised. I know of only one suspected case of Weil's disease within the team, but this was never positively diagnosed.

Our biggest worry is the common cold! It disrupts training and everyone is concerned about banned drugs, so we usually take nothing, which makes you a social outcast as no one wants to catch it!

As highly trained athletes our immune system seems to be under stress, and we seem to be susceptible to any illness lurking around. It may be that canoeists catch these bugs in the aerosol produced from the water, develop cold symptoms and later a chest complaint. On the other hand, we do not seem to pick up any gastrointestinal illness from the river water, even as the water levels change through the year.

The biggest worry is developing a respiratory problem at a selection race or important international event. When 100ths of a second may separate you from a place in the team or a medal, feeling 100 per cent fit is essential. We all try the natural remedies, such as vitamin C, but is there any more we might do to keep these bugs at bay? Do other water sports have similar problems?

SHAUN PEARCE British Canoe Slalom Champion 